\title{
Microglial responses to peripheral type 1 interferon
}

\author{
Ernest Aw ${ }^{1,2}$, Yingying Zhang ${ }^{1}$ and Michael Carroll ${ }^{1 *}$ D
}

\begin{abstract}
Background: Interferon a (IFNa) is a cytokine whose production is increased endogenously in response to viral infection and in autoimmune diseases such as systemic lupus erythematosus (SLE). An elevated IFNa signature has been associated with clinically observed neuro-behavioural deficits such as mild cognitive impairment, fatigue, depression and psychosis in these diseases. However, the mechanisms underlying these neuropsychiatric symptoms remain largely unknown, and it is as yet unclear how IFNa signalling might influence central nervous system (CNS) function. Aberrant microglia-mediated synaptic pruning and function has recently been implicated in several neurodegenerative and neuropsychiatric diseases, but whether and how IFNa modulates these functions are not well defined.
\end{abstract}

Methods: Using a model of peripheral IFNa administration, we investigated gene expression changes due to IFNAR signalling in microglia. Bulk RNA sequencing on sorted microglia from wild type and microglia-specific Ifnar 1 conditional knockout mice was performed to evaluate IFNa and IFNAR signalling-dependent changes in gene expression. Furthermore, the effects of IFNa on microglia morphology and synapse engulfment were assessed, via immunohistochemistry and flow cytometry.

Results: We found that IFNa exposure through the periphery induces a unique gene signature in microglia that includes the expected upregulation of multiple interferon-stimulated genes (ISGs), as well as the complement component C $4 b$. We additionally characterized several IFNa-dependent changes in microglial phenotype, including expression of CD45 and CD68, cellular morphology and presynaptic engulfment, that reveal subtle brain regionspecific differences. Finally, by specifically knocking down expression of IFNAR1 on microglia, we show that these changes are largely attributable to direct IFNAR signalling on microglia and not from indirect signalling effects through other CNS parenchymal cell types which are capable of IFNa-IFNAR signal transduction.

Conclusions: Peripheral IFNa induces unique genetic and phenotypic changes in microglia that are largely dependent on direct signalling through microglial IFNAR. The IFNa-induced upregulation of C $4 b$ could play important roles in the context of aberrant synaptic pruning in neuropsychiatric disease.

Keywords: Microglia, Interferon alpha (IFNa), Interferon-stimulated gene (ISG), Complement, Synapse engulfment, Neuropsychiatric

\footnotetext{
* Correspondence: michael.carroll@childrens.harvard.edu

'Program in Cellular and Molecular Medicine, Boston Children's Hospital, Boston, MA, USA

Full list of author information is available at the end of the article
}

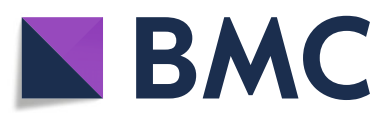

(c) The Author(s). 2020 Open Access This article is licensed under a Creative Commons Attribution 4.0 International License, which permits use, sharing, adaptation, distribution and reproduction in any medium or format, as long as you give appropriate credit to the original author(s) and the source, provide a link to the Creative Commons licence, and indicate if changes were made. The images or other third party material in this article are included in the article's Creative Commons licence, unless indicated otherwise in a credit line to the material. If material is not included in the article's Creative Commons licence and your intended use is not permitted by statutory regulation or exceeds the permitted use, you will need to obtain permission directly from the copyright holder. To view a copy of this licence, visit http://creativecommons.org/licenses/by/4.0/. The Creative Commons Public Domain Dedication waiver (http://creativecommons.org/publicdomain/zero/1.0/) applies to the data made available in this article, unless otherwise stated in a credit line to the data. 


\section{Introduction}

Type 1 interferons are a family of cytokines classically implicated in antiviral defence, but also play important pathological roles when their expression is dysregulated, such as in the autoimmune diseases Aicardi-Goutières syndrome (AGS) and systemic lupus erythematosus (SLE) $[1,2]$. Interferon $\alpha$ (IFN $\alpha$ ) belongs to the type 1 interferon family, which also include IFN $\beta$ and other lesser studied IFNs; it comprises 14 different isoforms in mice and 13 in humans that are highly conserved in gene structure and amino acid sequence [3]. All type 1 interferons signal through the type 1 interferon receptors IFNAR1 and IFNAR2, which dimerize upon ligand binding and activate the JAK1 and TYK2 receptor tyrosine kinases (RTKs). Canonically, these RTKs phosphorylate the STAT1 and STAT2 transcription factors resulting in their translocation into the nucleus, where, with IRF9 they form the transcription factor complex ISGF3. ISGF3 binds to IFN-stimulated response elements (ISRE) on promoters, inducing gene expression programmes involving interferon-stimulated genes (ISGs) that are commonly antiviral and antiproliferative [3, 4]. Interestingly, the ISG expression landscape differs across cell types in a manner that is dependent on signalling strength and chronicity, as well as the activation of other non-canonical signalling machinery, resulting in functionally distinct outcomes $[3,4]$.

Importantly, IFN $\alpha$ has been closely associated with numerous neuropsychiatric comorbidities in various clinical contexts, including recombinant IFNa treatment for chronic hepatitis $C$ infection and melanoma [5-7], as well as SLE associated neuropsychiatric disease $[8,9]$. These neuropsychiatric deficiencies are heterogeneous in presentation, ranging in severity from mild cognitive dysfunction and fatigue to overt psychosis. Despite its well-studied signal transduction pathway in terms of antiviral function, it is as yet unclear how IFNo-IFNAR signalling within the brain translates to such detrimental neuropsychiatric outcomes. Furthermore, given the ubiquitous capacity of most nucleated cell types to respond to IFNAR signalling, it is unclear which cell types within the central nervous system (CNS) are critical, functional contributors to IFN $\alpha$-associated neuropsychiatric disease.

Microglia are long-lived tissue-resident macrophages of the brain and play important roles in shaping neuronal circuits during development via synaptic pruning $[10,11]$, while also constantly surveying the brain parenchyma to detect injury or damage [12, 13]. Aberrant microglial function linked to dysregulated synaptic pruning has been implicated in the pathophysiology of several neurodegenerative and neuropsychiatric diseases including Alzheimer's disease (AD) [14, 15], schizophrenia [16] and autism spectrum disease $[17,18]$. Furthermore, microglia have been shown to secrete pro-inflammatory cytokines that negatively impact neurogenesis and influence depressive behaviour in response to peripherally derived IFN $\alpha$ [19], and dysregulation of IFNAR signalling in white matter microglia via genetic attenuation of its negative regulator $U_{s p} 18$ causes destructive microgliopathy in the brain [20]. Interestingly, recent sequencing studies have identified a microglial type 1 IFN gene signature in the contexts of ageing [21, 22], Alzheimer's disease [15, 23] and SLE [24], suggesting a potential unifying role of type 1 IFN signalling in propagating the neurological and neuropsychiatric pathologies in these variable pathological contexts. However, despite the increasingly appreciated role of IFN $\alpha$ in inflammation-associated CNS pathology, it is still unclear how IFN $\alpha$ regulates microglial function, and whether it might influence microglia-mediated synaptic pruning as a potential mechanism in driving IFNoassociated neuropsychiatric disease.

In the present study, we report that peripherally derived IFN $\alpha$ is able to transduce signalling across the blood-brain barrier (BBB), resulting in a unique microglial genetic signature that is primarily dependent on microglial IFNAR. Our results also demonstrate that in an acute model of IFN $\alpha$ exposure, microglia adopt a unique activated state and engulf synaptic material in a brain region-dependent manner. In light of recent studies implicating the complement system in both homeostatic and pathological synaptic pruning $[10,14,25]$, the IFNo-mediated upregulation of complement component $C 4 b$ expression in microglia may contribute to IFN $\alpha$-related neuropsychiatric symptoms by a similar mechanism.

\section{Materials and methods}

\section{Animals}

Eight-week-old male and female C57BL/6J (000664) mice were purchased from Jackson Laboratories. Injections of PBS and murine recombinant IFNa-A (mIFNa) (BioLegend) were all performed intraperitoneally at 8 weeks of age for C57BL/6 mice. Daily injections were performed around between 0800 and $0900 \mathrm{~h}$ each day for 7 days, and mice were sacrificed $3 \mathrm{~h}$ post final injection. Cx3cr1CreERT2 (020940) and R26-Eyfp ${ }^{\text {LSL }}$ (006148) mice were purchased from Jackson Laboratories. R26-Eyfp ${ }^{L S L}$ mice were backcrossed to the C57BL/6 background in house for at least 10 generations. Ifnar ${ }^{f l / f l}$ (MGI:2655303) mice were obtained from Ulrich Kalinke. Cx3cr1-CreERT2 mice were crossed with Ifnar $f^{f l / f l}$ or R26-Eyfp ${ }^{L S L}$ mice to obtain Cx3cr1-CreERT2 ${ }^{+/}$, Ifnar ${ }^{f l f l}$ and Cx3cr1-CreERT2 ${ }^{+/}$, R26$E y f p^{L S L}$ mice respectively. CreERT2 activity was induced by oral gavage of either sunflower seed oil vehicle (Spectrum Chemical) or $100 \mathrm{mg} / \mathrm{kg}$ body weight tamoxifen (Sigma) daily for 5 days at 8 weeks of age. Recycling monocytic/ macrophagic populations were allowed to replenish themselves for 4 weeks [26] prior to sacrifice or mIFN $\alpha$ injections. Male and female mice were used for all experiments, except for the determination of serum mIFN levels, where 
only male mice were used. All animal experiments were approved by the Boston Children's Hospital and Harvard Medical School institutional animal use and care committee in accordance with $\mathrm{NIH}$ guidelines for the humane treatment of animals.

\section{Serum ELISA for mIFNa}

Serum samples were assayed on the VeriPlex Mouse Cytokine 9-Plex ELISA Kit (PBL Assay Science) by contract service from the company (PBL Assay Science).

\section{Microglia purification}

Microglia were purified using an adapted protocol [27]. Briefly, mice were perfused with ice-cold PBS and brain regions were dissected into ice-cold HBSS without calcium, magnesium and phenol red (Corning). Tissue was Dounce homogenized using a 1-mL tissue grinder (Wheaton), with 12 slow strokes each on the loose followed by the tight pestle. The cell suspension was then spun down at $1200 \mathrm{rpm}, 7 \mathrm{~min}$ at $4{ }^{\circ} \mathrm{C}$ and resuspended in 70\% Percoll (GE Healthcare). Thirty-seven percent Percoll was carefully layered on top and spun down at $800 \mathrm{~g}, 25 \mathrm{~min}$ at $23^{\circ} \mathrm{C}$ with the acceleration set to 3 and deceleration set to 2 on a Sorvall Legend XTR centrifuge (Thermo Fisher). The cloudy cellular layer was then carefully pipetted and diluted in ice-cold FACS buffer (0.1\% BSA, 1 mM EDTA in PBS). Cells were then processed for downstream staining for flow cytometry or fluorescence activated cell sorting (FACS). For flow cytometric assessment of presynaptic engulfment of synaptic vesicle 2 (SV2), $10 \mu \mathrm{M}$ cytochalasin D (Sigma) was added to HBSS and all Percoll dilutions.

\section{Flow cytometry and sorting}

Cells were stained with primary antibodies against CD11b (clone M1/70, Biolegend), CD45 (clone 30-F11, Biolegend), fixable viability dye eFluor-780 (eBioscience) for $30 \mathrm{~min}$ at $4{ }^{\circ} \mathrm{C}$. For intracellular staining, cells were fixed using fixation buffer (Biolegend) and permeabilized using intracellular fixation and permeabilization buffer (Biolegend) according to manufacturer's instructions. Fixed and permeabilized cells were stained with primary antibodies against CD68 (clone FA-11, Biolegend) and SV2 (DSHB, UIowa). SV2 monoclonal antibodies were purified and conjugated to fluorochromes in-house. Flow cytometry was performed on a FACSCanto (BD Biosciences), and microglial sorting was performed on a FACS Aria II SORP (BD Biosciences) using a 70- $\mathrm{mm}$ nozzle. Data was analysed using FlowJo (Tree Star).

\section{Immunohistochemistry}

Mice were perfused with ice-cold PBS, and brains were dissected and fixed in 4\% PFA (Electron Microscopy Sciences) overnight at $4{ }^{\circ} \mathrm{C}$. Tissue was cryopreserved in
$30 \%$ sucrose, followed by embedding in OCT (Fisher Healthcare) and cryosectioned into $40-\mu \mathrm{m}$-thick floating sections. Tissue sections were blocked for $1 \mathrm{~h}$ at RT with blocking buffer (5\% BSA, $0.2 \%$ Triton-X in PBS) and stained with primary antibody against IBA1 (Wako, 1: 400 ) overnight at RT. Tissue sections were then washed $3 \times$ in PBS, stained with secondary antibody against rabbit IgG (Invitrogen, 1:200) for $1 \mathrm{~h}$ at RT, washed $3 \times$ with PBS and then mounted onto a slide with mounting medium with DAPI (Southern Biotech) and sealed with nail varnish. Primary and secondary antibodies were diluted in blocking buffer.

\section{Microglia morphology analysis}

Confocal images of the tissue sections were obtained at $\times 60$ magnification using the FV1000 confocal system (Olympus). Three fields of view from 2 brain sections each of the frontal cortex, hippocampus and cerebellum per biological sample were imaged and analysed using Cell Profiler [28]. Briefly, microglia were identified and segmented based on IBA1 staining, and various area and shape features were derived using the MeasureObjectSizeShape module of Cell Profiler. Pipeline used is available upon request.

\section{RNAscope in situ hybridization and analysis}

Mouse brains were dissected and snap frozen on dry ice following terminal anaesthesia, without perfusion. OCT embedded brains were then cryosectioned into $16-\mu \mathrm{m}$ thick sections prior to RNAscope in situ hybridization. RNAscope in situ hybridization was performed using the RNAscope fluorescent multiplex assay kit (ACD Bio) using probes directed against $M x 1$ (474931, ACD Bio), Rsad2 (561251, ACD Bio) and Tmem119 (472901, ACD Bio) according to manufacturer's instructions. Confocal images were obtained at $\times 40$ magnification using the FV1000 confocal system (Olympus). Three fields of view of the frontal cortex per biological sample were imaged and analysed using Cell Profiler [28]. Briefly, microglia were classified as DAPI+ cells containing more than 2 Tmem119 puncta, and cells were defined as ISG positive if they expressed more than 1 identified puncta of $M x 1$ or Rsad2. Pipeline used is available upon request.

\section{Gene expression by qPCR and ddPCR}

Brain or spleen tissue was homogenized in TRIzol reagent (Ambion) using the TissueLyser homogenizer (Qiagen) and RNA was isolated by phenol-chloroform extraction. For microglia-specific gene expression assays, microglia were directly sorted into TCL lysis buffer (Qiagen) supplemented with $1 \% \beta$-mercaptoethanol (Sigma). RNA was extracted using 2.2X RNAclean XP beads (Beckman Coulter) following manufacturer's instructions. cDNA was then synthesized with gDNA depletion using the iScript gDNA 
clear cDNA synthesis kit (BioRad) following manufacturer's instructions. qPCR reactions were assembled for genes of interest (Actb, Ifnar1) using the iTaq universal SYBR Green supermix system (BioRad) and run on a CFX96 machine (BioRad). Digital Droplet PCR (ddPCR) (BioRad) reactions were assembled according to manufacturer's instructions, using manufacturer probes for genes of interest except for Eif4h, Rpp30 and C4b. For qPCR, gene expression was normalized to Actb and compared using the $\Delta \Delta C_{t}$ method. For ddPCR, gene expression was normalized to Eif4h for microglia or Rpp30 for spleen.

qPCR primers are as follows: Actb (forward: $5^{\prime}$ AAGAGC TATGAGCTGCCTGA reverse: 5 ' TACGGATGTCAACG TCACAC) and Ifnarl (forward: 5'TGTGCTTCCCACCACTCAAG, reverse: 5' AGGCGCGTGCTTTACTTCTA).

ddPCR primer/probe sets are as follows: $M x 1$ (dMmu CPE5121908, BioRad), Ifit3 (dMmuCPE5197126, BioRad), Oas2 (dMmuCPE5099434, BioRad), Axl (dMmuCPE5090 992, BioRad), Eif4h (forward: 5' TGCAGCTTGCTTGGTA GC, reverse: 5' GTAAATTGCCGAGACCTTGC, probe: 5' HEX-AGCCTACCCCTTGGCTCGGG), Rpp30 (forward: 5' TGACCCTATCAGAGGACTGC, reverse: $5^{\prime}$ CTCTGCAA TTTGTGGACACG, probe: 5'HEX- TGGGCTTTCTGA AAATGATGGCAA) and $C 4 b$ (forward: 5' AGCCTGTTTC CAGCTCAAAG, reverse: 5' GTCCTAAGGCCTCAC ACC TG, probe: 5'FAM- CCCCGGCTGCTGAACTCCAT).

\section{Microglia bulk RNAseq and analysis}

One thousand and two hundred microglia from anterior cortex, spanning the frontal, motor and part of the somatosensory cortices were sorted into TCL buffer supplemented with $1 \% \beta$-mercaptoethanol, and RNA was extracted using RNAclean XP beads as described. cDNA was synthesized using the SMART-Seq v4 ultra-low input kit for RNA sequencing (Takara Bio) according to manufacturer instructions. Library preparation for sequencing was performed using the Nextera XT DNA library prep kit (Illumina) according to the manufacturer's instructions. Sample quality was assayed as recommended using the high sensitivity DNA kit (Agilent). Samples were pooled equimolarly and sequencing was performed on a Nextseq 500 sequencer (Illumina) with $1 \mathrm{nM}$ input. For bulk RNAseq analysis, $75 \mathrm{bp}$ single-end reads were first trimmed of their adaptors and then aligned to the $\mathrm{mm} 10$ mouse reference genome using STAR Aligner [29]. All samples had at least 20 million uniquely mapped reads. The raw read count matrix was then analysed in the EdgeR package [30] for differential gene expression using the QLF model. Gene ontology analysis was performed using the gProfiler2 package [31].

\section{Statistical analysis}

For all statistical analysis, $\mathrm{R}$ and GraphPad Prism 8 (GraphPad Software) were used. Error bars represent s.d. in all figures. All replicate numbers, statistical tests, $p$ values and $q$ values used are indicated in the figure legends where appropriate. Statistical tests were selected based on the normality of the data distribution, assessed by the Shapiro-Wilk test or quantile-quantile (QQ) plot, and also the equality of variance, assessed by the $F$ test.

\section{Results}

\section{Titration of peripherally administered $\mathrm{mIFNa}$}

In order to determine whether peripherally administered murine recombinant interferon $\alpha(\mathrm{mIFN} \alpha)$ was able to induce a signalling effect within the central nervous system (CNS), mice were injected intraperitoneally with varying doses of mIFN $\alpha$. To model acute type 1 interferonmediated inflammation, mice were injected daily for 7 days (Fig. 1a), and a dose-dependent, titratable effect on interferon-stimulated gene (ISG) expression both in the spleen (Fig. 1b) and in perfused cortical tissue from the brain (Fig. 1c) was observed. A working dose of $10 \mathrm{ng}$ $\mathrm{mIFN \alpha} / \mathrm{g}$ of body weight was selected and used for all further experiments, which is of similar dosage used in previous studies and also within the relative dose range that has been used therapeutically in patients with chronic hepatitis C infection or various cancers [19, 32-36]. Furthermore, serum concentrations of mIFN $\alpha$ averaged at around 200 $\mathrm{pg} / \mathrm{mL} 3 \mathrm{~h}$ post final injection using this dosing schedule (Fig. 1d), indicating a roughly 600 -fold decrease in bioavailability at this time point, assuming a total blood volume of $2 \mathrm{~mL}$ for a 25 -g male mouse. Given the induced ISG signature, we observed in the spleen and brain cortex at this same time point, it is reasonable to assume that at least part of this large decrease in bioavailability was due to cellular or tissue consumption and signal transduction of mIFN $\alpha$ as manifested by their ISG signature.

\section{Peripherally administered mIFNa induces ISG expression in microglia}

The blood-brain barrier (BBB) tightly regulates the movement of a wide range of molecules, including cytokines, to and from the CNS [37]. Given the recent appreciation that microglia play critical immunological roles in surveying and protecting the CNS from pathogenic threats and injury [12, 13, 25], it was next investigated whether peripherally administered mIFN $\alpha$ would be able to induce IFNAR signalling in microglia across the BBB. Indeed, using RNAscope in situ hybridization, peripherally administered mIFN $\alpha$ increased expression of the ISGs $M x 1$ and Rsad2, in up to $75 \%$ of microglia (Tmem119-positive cells) within the frontal cortex (Fig. $1 \mathrm{e}, \mathrm{f})$. We note that increased numbers of ISG puncta were also present in non-Tmem119 positive cells (Fig. 1g), suggesting that peripherally administered mIFN $\alpha$ is also able to induce functional IFNAR signalling in cell types other than microglia within the CNS. 


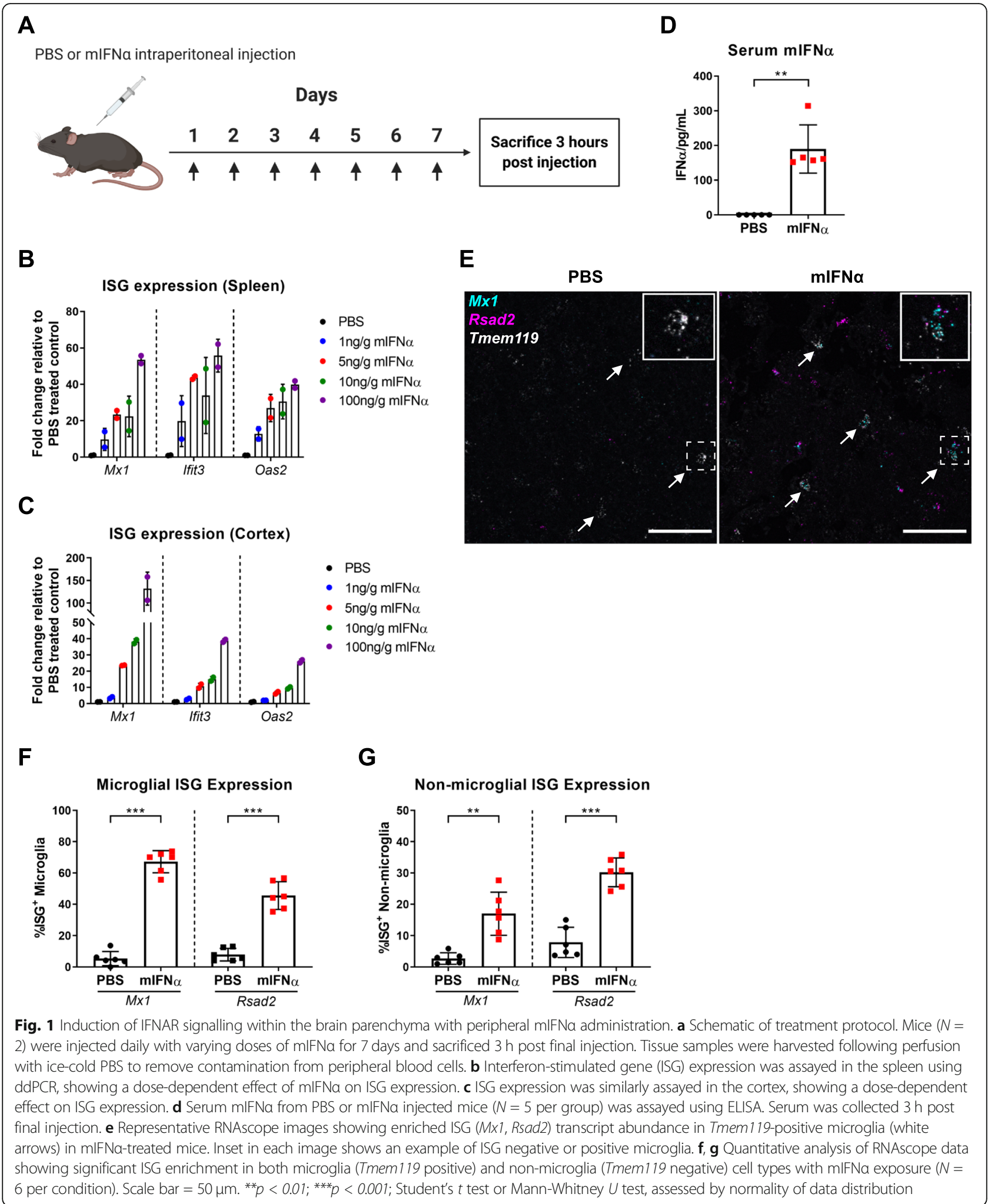

A genetic and phenotypic mIFNa signature in microglia IFN $\alpha$ therapy commonly induces a variety of sickness behaviours that include fatigue, anhedonia and paresthesia
[5, 38, 39]. While the neurological bases of these sickness behaviours remain incompletely characterized, they have been associated with specific brain regions including the 
prefrontal and sensorimotor cortices [40-42]. Therefore, in order to further investigate mIFN $\alpha$-induced genetic changes in microglia in a behaviourally relevant brain region, bulk RNA sequencing on sorted microglia from the anterior cortex spanning the frontal, motor and part of the somatosensory cortices (Supplementary Figure 1) was performed. Analysis of differentially expressed (DE) genes revealed the expected upregulation of many ISGs, as well as a few members of the complement gene family, in particular $C 4 b$ (Fig. 2a). Additionally, mIFN $\alpha$ treatment also altered the expression profile of several microglial cytokine and sensome [44] genes (Supplementary Figures 1D, E), the latter being previously defined as a set of protein encoding genes that function as sensors of endogenous ligands and microbes. We next performed gene ontology (GO) analysis using gProfiler2 [31] to identify functional pathways altered by mIFNa (Fig. 2b). As expected, type 1 IFN response pathways, which included the phagocytic and class $1 \mathrm{MHC}$ antigen presentation programmes, were found to be significantly altered. Many significantly altered GO terms relating to cellular metabolism, which included the terms "autophagy" and "cellular catabolic process", were also observed. Finally, the increased expression of some of the identified DE genes was validated by ddPCR of sorted cortical microglia from mIFN $\alpha$-treated mice (Fig. 2c). Aberrant synapse pruning by microglia has been implicated in both neurodegenerative and neuropsychiatric disease [14, 17], and it remains unclear whether acute exposure to mIFNa would result in any changes to microglia-mediated synapse pruning. It has been previously shown that peripheral IFN $\alpha$ injection induces an enriched ISG signature in the hippocampus and cerebellum compared to other anatomical regions in the rodent brain [33]. Given the known associations of these brain regions to the cognitive deficiencies and anxiety behaviours associated with IFN $\alpha$ treatment [45-48], microgliamediated synaptic engulfment was assessed in the hippocampus and cerebellum in addition to the frontal cortex, which has also been implicated in these sickness behaviours $[46,49]$. Using a flow cytometry-based method to detect intracellular presynaptic particles (SV2) within microglia (Supplementary Figure 2), it was found that peripheral mIFN $\alpha$ treatment only modestly increased intracellular SV2 in cerebellar microglia, but not in microglia from either the frontal cortex or hippocampus (Fig. 3a). To ascertain if there were any changes in expression of

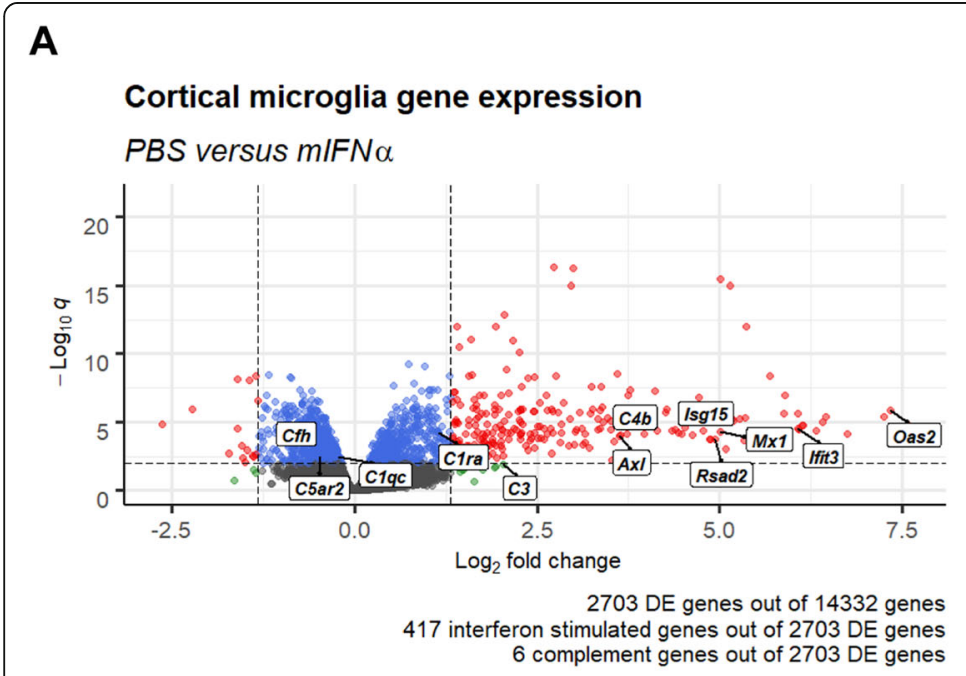

B
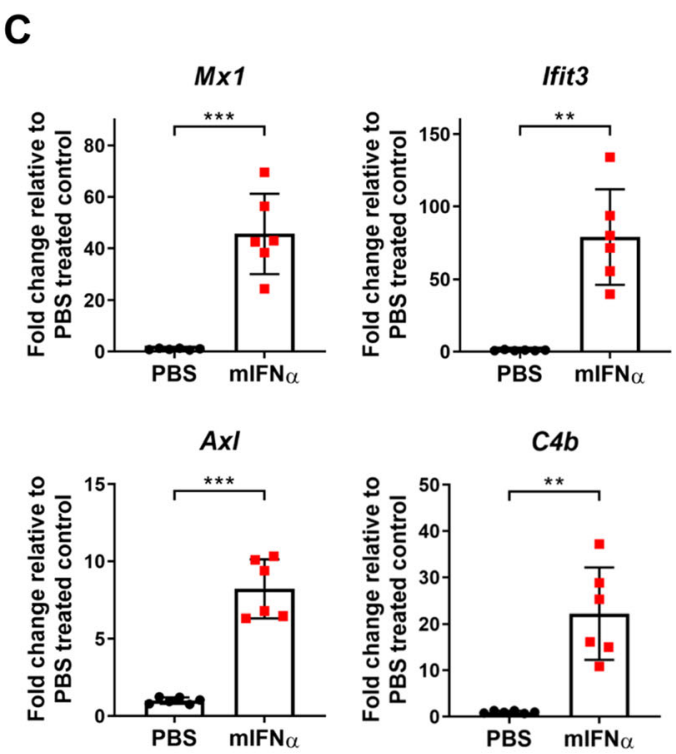

\begin{tabular}{|llll|}
\hline GO Term ID & GO Term Name & Intersection $\%$ & q value \\
\hline GO:0048002 & Antigen processing and presentation of peptide antigen & 57.1 & $8.64 \mathrm{E}-07$ \\
\hline GO:0006909 & Phagocytosis & 36.1 & $2.87 \mathrm{E}-06$ \\
\hline GO:0044248 & Cellular catabolic process & 22.1 & $2.51 \mathrm{E}-04$ \\
\hline GO:0035455 & Response to interferon-alpha & 52.2 & $3.57 \mathrm{E}-03$ \\
\hline GO:0006914 & Autophagy & 25.4 & $5.18 \mathrm{E}-03$ \\
\hline
\end{tabular}

Fig. 2 Transcriptional profiling of mIFNa exposed microglia. a Volcano plot showing highlights of differentially expressed (DE) genes from bulk RNA sequencing of sorted cortical microglia. Interferon-stimulated genes were identified based on querying the Interferome 2.0 database [43] with the DE gene list. $q$, Benjamini-Hochberg adjusted $p$ value. Dotted lines demarcate $q=0.01$ and fold change $=2.5$. $\mathbf{b}$ A selection of differential gene ontology pathways identified using gProfiler2 [31] enriched in mIFNa exposed microglia. c Validation of several interferon-stimulated genes (ISGs) by ddPCR on sorted cortical microglia from an independently treated cohort of mice. $N=6$ for all data shown. ${ }^{* *} p<0.01 ;{ }^{* * *} p<0.001$; Student's $t$ test 


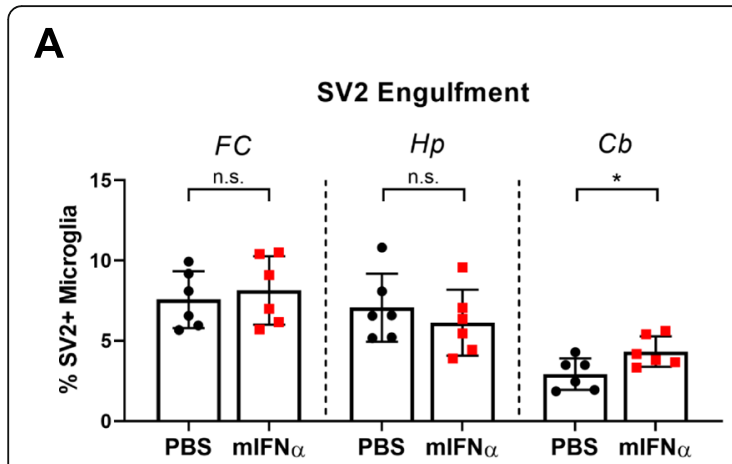

B

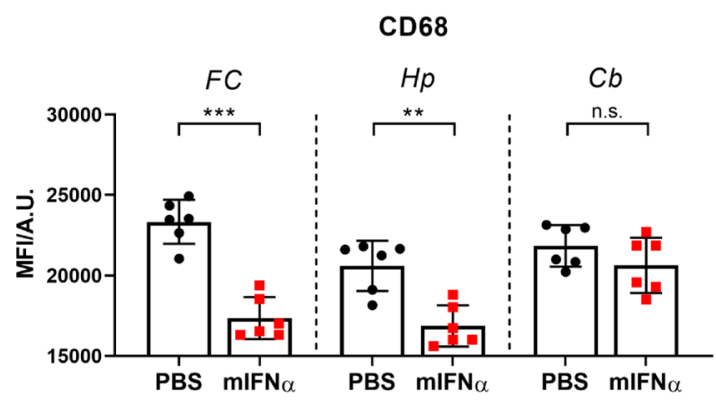

CD45

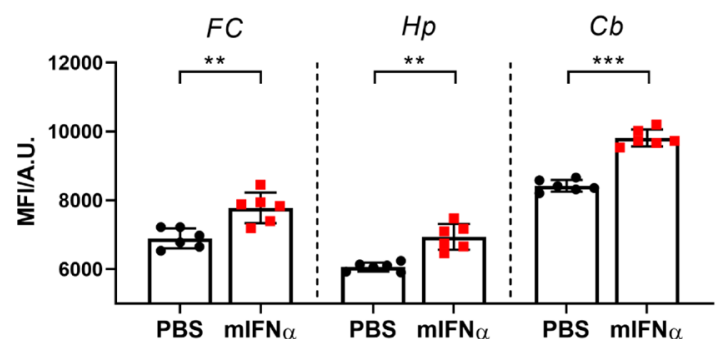

C
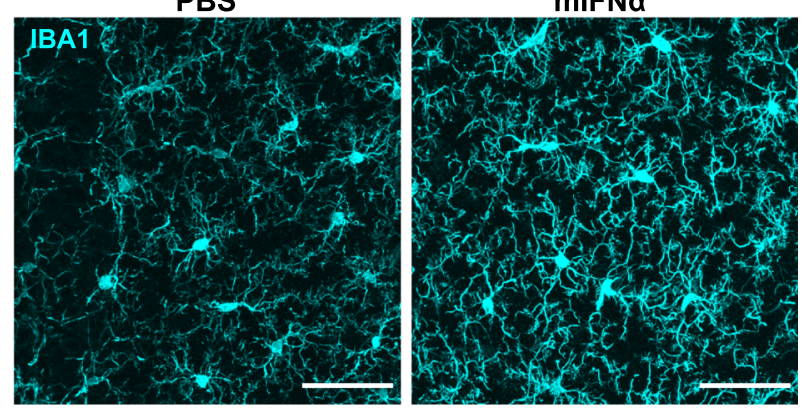

D

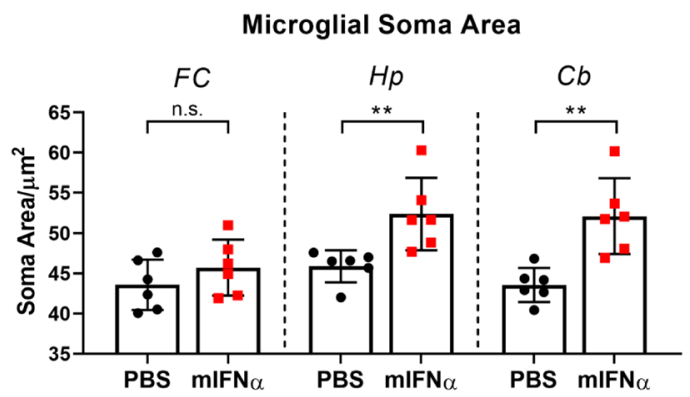

Microglial Cell Perimeter

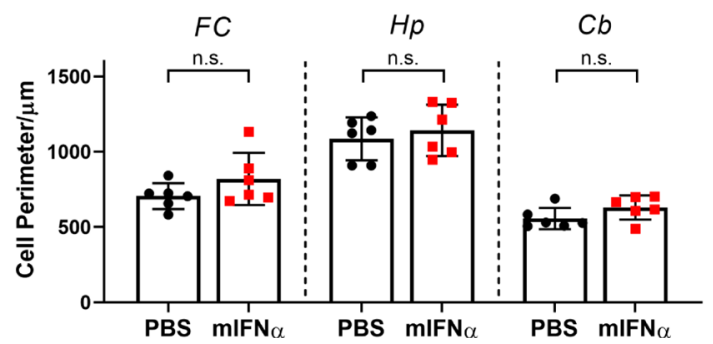

Fig. 3 Microglial IFNAR signalling results in unique changes in classical activation parameters. a Selectively enhanced microglial synapse engulfment in the cerebellum with mIFNa exposure. $\mathbf{b}$ mIFNa-induced changes in microglial surface expression of CD68 (decrease) and CD45 (increase) across different brain regions. $\mathbf{c}$ Representative images of microglia from the hippocampus from both treatment groups. Scale bar $=$ $50 \mu \mathrm{m}$. $\mathbf{d}$ Analysis of morphological changes in microglia with mIFNa exposure, showing brain region-specific differences. $N=6$ for all data shown. n.s., $p>0.05 ;{ }^{*} p<0.05 ;{ }^{* *} p<0.01$; *** $p<0.001$; Student's $t$ test or Mann-Whitney $U$ test, assessed by normality of data distribution

markers of microglial activation, flow cytometric analyses of CD68 and CD45 expression levels, which are associated with microglial activation and inhibition of activation, respectively [50, 51], were performed. There was a statistically significant decrease in CD68 expression in microglia from both the frontal cortex and hippocampus, and a trend towards decreased expression in the cerebellum (Fig. 3b). CD45 expression was significantly increased in all 3 brain regions assayed (Fig. 3b), suggesting a classically defined hypo-activated microglial state. Furthermore, immunohistological analyses of microglial morphology suggested a unique mIFNo-induced morphological state, with microglia displaying significantly increased soma size (associated with microglial activation), and a trend towards increased cell perimeter, which was used as a proxy measure for process ramification (Fig. 3c, d). These results suggest the possibility that acute mIFN $\alpha$ exposure induces a unique phenotypic state within microglia that displays subtle brain region-specific variability, which could potentially be due to region-specific levels of immune signalling module expression in microglia [52].

Knockdown of microglial IFNAR signalling attenuates the mIFNa genetic signature and phenotype

Due to the ubiquitous nature of IFNAR expression in multiple cell types, it is possible that mIFNa might induce secondary signalling effects on microglia that are downstream of IFNAR signalling in these different cell types. For example, these effects could occur via the production of other cytokines or chemokines, such as 
CXCL10 from brain endothelial cells [53], or even IL-6, IL-1 $\beta$ and TNF $\alpha$ from microglia [19] in response to type 1 interferon signalling. Indeed, significant gene expression upregulation of several of these cytokines and chemokines in mIFNo-exposed microglia were observed (Supplementary Figure 1E), which could potentially contribute towards autocrine signalling effects. Furthermore, many ISGs can also be cross regulated by distinct signalling pathways downstream of other cytokines, such as IL-1 $\beta$, IFN $\gamma$ and TNF $\alpha$ [54-57]. Given the increased expression of some of these cytokines in response to IFN $\alpha$ (Supplementary Figure 1E), it is possible that the observed canonical ISG signature is additionally derived in part by other cytokine signalling pathways.

In order to further investigate whether the IFNainduced phenotypic and genetic changes in microglia can primarily be attributed to direct microglial IFNAR signalling, Ifnar 1 expression on microglia was selectively knocked down using the inducible Cx3cr1-CreERT2 driver [26] (Supplementary Figure 3; Fig. 4a, b). Indeed, $\mathrm{mIFN \alpha}$ treatment of mice with microglial specific knockdown of Ifnarl resulted in the attenuation of ISG expression, as well as $C 4 b$ expression, in microglia compared to control mice (Fig. 4c), suggesting that these genes are directly regulated by microglial IFNAR signalling. Furthermore, there was a reversal of the SV2 engulfment phenotype in cerebellar microglia with knockdown of microglial Ifnar1, with no corresponding significant change in microglial SV2 engulfment in both the frontal cortex and hippocampus (Fig. 4d). Changes in microglial CD68 and CD45 expression levels were also largely reversed with knockdown of microglial Ifnarl (Fig, 4e).

Finally, the possibility of any potential non-microglial IFNAR signalling effects was investigated by bulk RNA sequencing of microglia sorted from the same anterior cortex region of Ifnarl sufficient and deficient mice treated with mIFNo (Supplementary Figure 4). As expected, knockdown of Ifnarl on microglia attenuated many of the genes induced by mIFN $\alpha$ as described earlier (Fig. 5a), with most of the DE genes displaying the highest $\log _{2}$ fold change ( $>1.5$ ) overlapping in identity with similarly high $\log _{2}$ fold change DE genes from mIFNo-exposed wild type microglia (Fig. 5b). Furthermore, the GO terms from both sets of experiments remained similar (Fig. 5c, d). Finally, the panel of sensome and cytokine/chemokine genes that were differentially expressed remained similar as well (Supplementary Figures 4C, D).

These data suggest that peripherally derived IFN $\alpha$ can induce a functional signalling event through microglia by upregulating a unique genetic and phenotypic programme. These genetic and phenotypic changes rely primarily on microglial IFNAR signalling and are largely independent of any potential secondary signalling effects through other cytokines or chemokines.

\section{Discussion}

To investigate the interaction of peripheral IFNa with the CNS, in particular microglia, we first show that peripherally administered mIFN $\alpha$ is able to exert direct functional signalling effects across the BBB on microglia. This is in agreement with previous studies which have shown that IFN $\alpha$ can enter the brain parenchyma from the periphery via a non-saturable mechanism $[59,60]$, and also elicit a transcriptional response within numerous cell types in the brain parenchyma [33]. Gene expression differences were further characterized by RNA sequencing and showed an expected strong upregulation of genes associated with type 1 interferon signalling. Interestingly, we also found a strong increase in expression of the complement component $C 4 b$, which has previously been observed in the contexts of viral infection [61] and ageing [21, 23], in microglia that also concurrently express a strong type 1 interferon signature. In particular, we also show that IFNAR signalling on microglia results in a unique phenotype characterized by subtle morphological changes and changes in the classical activation markers CD45 and CD68 in a regionspecific manner. Furthermore, we also show an increase in microglial synaptic engulfment within the cerebellum but not in the hippocampus or frontal cortex with mIFN $\alpha$ exposure.

By specifically knocking down Ifnarl expression on microglia through the use of the inducible $C \times 3 \mathrm{cr} 1$ CreERT2 driver, we show that these genetic and phenotypic changes are largely due to direct signalling through microglial IFNAR. We acknowledge that direct comparison between our RNAseq datasets is not possible due to the experimental design and our resulting inability to correct the data for batch effects. We also cannot rule out the likely possibility that incomplete knockdown of Ifnarl on microglia diluted the significance and magnitude of DE genes, and consequently, gene ontology pathways identified. Nevertheless, we show that a sizeable proportion of highly DE genes and gene ontology pathways overlap across both datasets, suggesting a major contribution of direct microglial IFNAR signalling despite the experimental caveats.

It is increasingly appreciated that the complement pathway might play a significant role in the pathogenesis of several neurodegenerative [14] and neuropsychiatric [16] diseases and that it is also a driver of synapse loss in viral infection-associated cognitive decline [25]. In particular, recent studies have shown that overexpression of mouse $\mathrm{C} 4$ within the mouse prefrontal cortex or human $\mathrm{C} 4 \mathrm{~A}$ in the whole brain is sufficient to induce increased microglial synaptic pruning that results in impaired social behaviour [62]. We observed a modest, but statistically significant, increase in microglial presynaptic engulfment in the cerebellum, but not frontal cortex and 


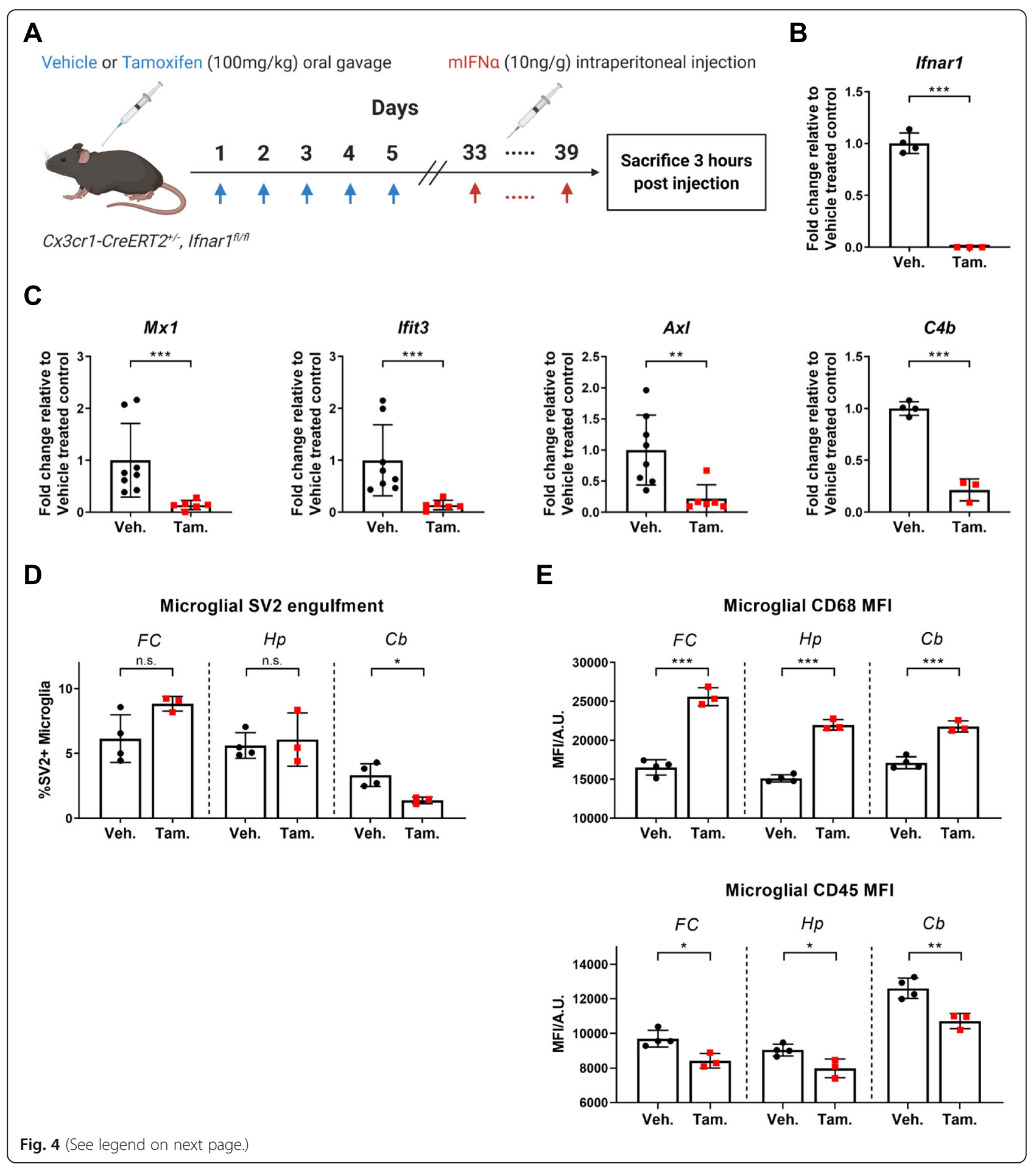


(See figure on previous page.)

Fig. 4 Knockdown of microglial IFNAR signalling attenuates phenotypic and genetic changes in response to peripheral mIFNa administration. a Schematic of treatment protocol. CX3Cr1-CreERT2 ${ }^{+/-}$, Ifnar $1^{f / f f l}$ mice were orally gavaged with either vehicle or tamoxifen. Four weeks post gavage, mice were either sacrificed (for qPCR validation of Ifnar 1 knockdown) or treated with mIFNa daily for 7 days and sacrificed. b Cortical microglia

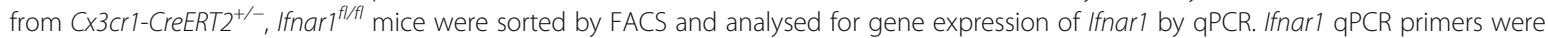
designed to span the floxed region of Exon 10. The tamoxifen-treated $(N=3)$ CreERT2-positive group showed significant knockdown of Ifnar1 expression compared to the vehicle-treated group $(N=4)$. c Sorted cortical microglia show significantly decreased ISG expression by ddPCR in

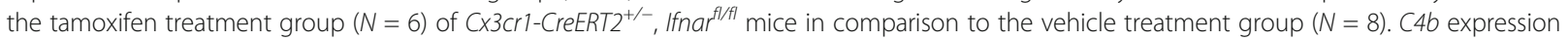
was also significantly decreased in the tamoxifen treatment group $(N=3)$ in comparison to the vehicle treatment group $(N=4)$. $\mathbf{d}$ Knockdown of microglial Ifnar 1 in the tamoxifen treatment group $(N=3)$ reverses the observed region-specific changes in synapse engulfment induced by peripheral mIFNa administration in comparison to the vehicle treatment group $(N=4)$. e Knockdown of microglial Ifnarl in the tamoxifen treatment group $(N=3)$ reverses the observed changes in CD45 and CD68 expression induced by peripheral mIFNa administration, with the exception of CD68 expression in the cerebellum in comparison to the vehicle treatment group $(N=4)$. Veh., Vehicle; Tam., Tamoxifen; n.S., $p>$ $0.05 ;{ }^{*} p<0.05 ;{ }^{* *} p<0.01$; ${ }^{* * *} p<0.001$; Student's $t$ test or Mann-Whitney $U$ test, assessed by normality of data distribution

hippocampus. While our RNA sequencing and ddPCR validation studies showed an $\mathrm{mIFN} \alpha$-induced increase in $C 4 b$ expression on sorted anterior cortex microglia, it is likely that cerebellar microglia also increase $C 4 b$ expression in response to $\mathrm{mIFN \alpha}$, given that at baseline they are in a more "immunologically vigilant" state with an enriched type 1 IFN regulatory signature, compared to cortical and hippocampal microglia [52]. The increase in presynaptic engulfment by cerebellar microglia compared to microglia from the other brain regions could thus be due to an enhanced signalling response to mIFN $\alpha$, a facet of which could include higher $C 4 b$ expression. Additionally, it is probable that within an acute period of mIFNa exposure, most neurons or synapses

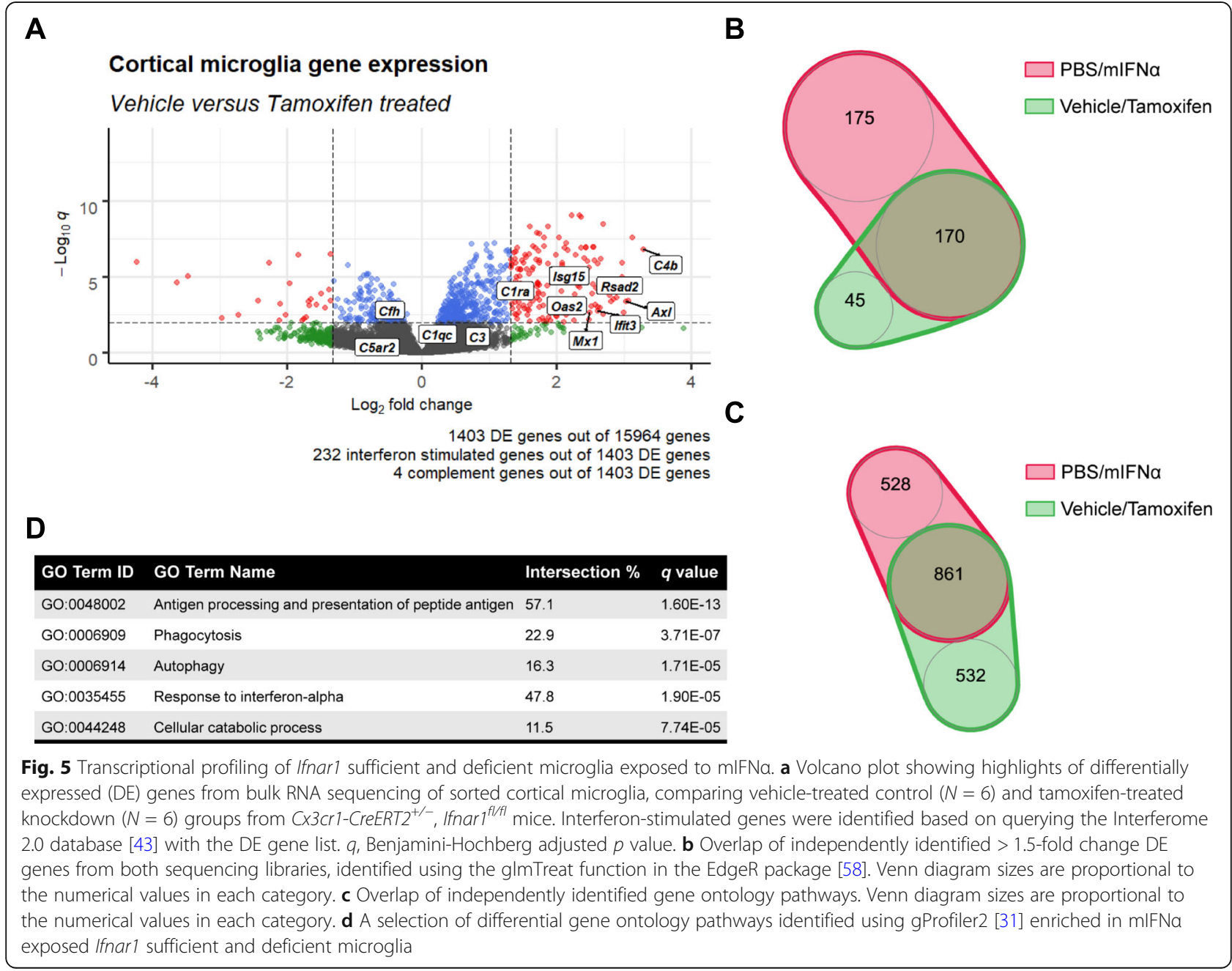


still express sufficient signals to prohibit synaptic engulfment, such as CD47 [63] and other complement regulatory factors. These regulatory signals and factors could be differentially distributed throughout different regions of the murine brain, resulting in differing levels of inhibition of complement activation and deposition. It should also be noted that our flow cytometric assay for synapse engulfment does not take into account any potential differences in the process of cargo degradation within the phagocytic pathway, although no significant differences in SV2 signal were observed when wild type, cortical microglia were exposed to chloroquine, an inhibitor of lysosomal acidification and acid-sensitive lysosomal proteases (data not shown). Furthermore, a previous study did not observe any differences in sensorimotor behaviour of mice injected daily with mIFN $\alpha$ for up to 5 weeks at a similar dose [32], which suggests that the small increase in synaptic engulfment we observe in the cerebellum might be phenotypically insignificant. However, it is possible that chronic IFNAR signalling within microglia and other CNS cell types could result in elevated C4 production and decreased complement and phagocytic inhibitory factors that over time could lead to the pathologic pruning of synapses. Of note, it was shown in the same study that chronic IFN $\alpha$ exposure $(\sim 4-5$ weeks $)$ in mice adversely affected neurogenesis and resulted in depressive behaviour [32]. Notably, endogenous IFNa can biochemically, and presumably functionally, cross signal through $\mu$-opioid receptors to exert anti-nociceptive effects $[64,65]$. It would therefore also be possible that the pathological effects of IFNa are mediated in part, or in tandem, through these secondary, or non-IFNAR signalling related processes.

Importantly, our study also shows a unique IFNainduced gene signature in microglia that bears similarity to other datasets presenting an enriched type 1 interferon signature in microglia within several pathological and biological contexts. GO analysis identified the expected terms for interferon responses and, also interestingly, metabolic changes in catabolism. While caution should be borne in interpreting the directionality of biological pathways based solely on gene ontology terms, we note that IFN $\alpha$ and viral infection have been found to generally induce a catabolic state in various cell types including macrophages [66-68]. Deficiencies in microglial autophagy have also been recently linked to impaired synaptic pruning and autism-like behavioural defects [17]. It would therefore be interesting to further probe how IFNAR signalling in microglia might modulate autophagic flux and whether increased autophagy in microglia might be a contributing mechanism for increased synaptic pruning in the context of chronic type 1 interferon exposure during autoimmune disease such as SLE.

\section{Conclusion}

In summary, we show that peripherally derived IFNa is able to signal directly across the BBB through microglial IFNAR. This results in a unique genetic and phenotypic profile that is primarily dependent on IFNAR signalling with minimal contribution from other secondary cytokine or chemokine signalling pathways. IFN $\alpha$-induced upregulation of $C 4 b$ and other ISGs might regulate various cellular functions and processes such as synaptic pruning in a brain region-dependent manner. These findings would be of further investigative interest given the long-standing association of endogenous and therapeutic IFN $\alpha$ with neuropsychiatric symptoms and the emerging therapeutic interest in IFN $\alpha$ use for prophylactic treatment of COVID19 [69-71].

\section{Supplementary Information}

Supplementary information accompanies this paper at https://doi.org/10. 1186/s12974-020-02003-Z.

Additional file 1: Figure S1. Microglia sorting and RNAseq data analysis. (A) Gating strategy for microglia cell sorting. (B) Principle component analysis (PCA) plot showing unbiased clustering of samples based on treatment group ( $\mathrm{N}=6$ per group). PC, Principal component. (C) Microglia specific genes were highly expressed in sorted microglia from both treatment groups. (D) Expression profile showing $\log _{2}$ fold change of microglial sensome genes [44] that are differentially expressed with mIFNa treatment. (E) mIFNa treatment induces significant changes in microglial gene expression of cytokines and chemokines. Normalized counts and differential expression testing were generated and performed using the EdgeR package [30].

Additional file 2: Figure S2. Flow cytometric assay of microglial synapse engulfment. (A) Schematic of experimental procedure for flow cytometric assaying of microglial SV2+ presynaptic engulfment. $10 \mu \mathrm{M}$ Cytochalasin D was added in buffers used during dounce homogenization and Percoll gradient centrifugation. (B) Effect of cytochalasin D treatment on the SV2 engulfment assay, showing the inhibition of active microglial phagocytosis of SV2 particles during tissue processing. Cortical tissue from opposing hemispheres in each mouse was perfused, dissected and processed with or without cytochalasin D, allowing for paired analysis of phagocytosis inhibition within the same mouse $(N=9)$. Veh., Vehicle; Cyto. $D$, Cytochalasin $D ; * *, p<0.01$; Wilcoxon's signed rank test. (C) Flow cytometric gating strategy for the engulfment assay. (D) Lack of neuronal debris adhering to microglia. Non permeabilized microglia show no fluorochrome signal compared to permeabilized microglia ( $N=3$ per treatment). P, Permeabilized; NP, Nonpermeabilized; ${ }^{*}, p<0.05$; Student's t test. (E) Isotype controls showing absence of non-epitope driven binding of SV2 and CD68 antibodies during intracellular staining.

Additional file 3: Figure S3. Validation of $\mathrm{C} \times 3 \mathrm{Cr} 1-\mathrm{CreERT2}$ targeting of microglia. (A) Schematic of treatment protocol. $\mathrm{C} \times 3 \mathrm{Cr} 1-\mathrm{CreERT2}{ }^{+/-}, \mathrm{R} 26-$ EYFP ${ }^{L S L}$ mice were orally gavaged with either vehicle $(N=2)$ or tamoxifen $(\mathrm{N}=3)$ and sacrificed 4 weeks post gavage. (B) Representative confocal images of frontal cortex of $C \times 3 \mathrm{Cr} 1-C$ reERT2 ${ }^{+-}$, $R 26$-EYFP ${ }^{L S L}$ mice showing specific expression of the $C \times 3 \mathrm{Cr} 1$-CreERT2 transgene in IBA1 expressing microglia/myeloid lineage cells. Scale bars $=200 \mu \mathrm{m}$. (C) Flow cytometric analysis of YFP expression in CD $11 b^{+}, C D 45^{10}$ microglia, showing elevated YFP expression only in the tamoxifen treated group. Veh., Vehicle; Tam., Tamoxifen.

Additional file 4: Figure S4. RNAseq analysis of anterior cortex microglia sorted from Ifnarl sufficient and deficient mice treated with mIFNa. (A) Principle component analysis (PCA) plot showing unbiased clustering of samples based on treatment group ( $N=6$ per group). $P C$, Principal component. (B) Microglia specific genes were highly expressed 
in sorted microglia from both treatment groups. (C) Expression profile showing $\log _{2}$ fold change of microglial sensome genes [44] that are significantly differentially expressed in Ifnarl sufficient vs. deficient microglia. (D) mIFNa treatment induces changes in microglial gene expression of cytokines and chemokines. Normalized counts and differential expression testing were generated and performed using the EdgeR package [30].

\section{Abbreviations}

AGS: Aicardi-Goutières syndrome; BBB: Blood-brain barrier; CNS: Central nervous system; DE: Differentially expressed; GO: Gene ontology;

IFNa: Interferon alpha; IFNY: Interferon gamma; mIFNa: Murine interferon alpha; IFNAR: Type 1 interferon receptor; IL-1 $\beta$ : Interleukin 1 beta; IL6: Interleukin 6; IRF9: Interferon regulatory factor 9; ISG: Interferon-stimulated gene; ISGF3: Interferon-stimulated gene factor 3; ISRE: Interferon-stimulated response element; JAK1: Janus kinase 1; RTK: Receptor tyrosine kinase; SLE: Systemic lupus erythematosus; STAT1: Signal transducer and activator of transcription 1; STAT2: Signal transducer and activator of transcription 2; SV2: Synaptic vesicle 2; TNFa: Tumour necrosis factor alpha; TYK2: Tyrosine kinase 2

\section{Acknowledgements}

We are grateful for the assistance of institute core facilities and helpful discussions with laboratory personnel, including the BCH/PCMM Microscopy Core, the BCH/PCMM Flow and Imaging Cytometry Resource, the DFCl Flow Core, the HMS Biopolymers Facility, Dr. Kristina Holton, Dr. Jessy Presumey and Khristina Holscher. Figure schematics were created using Biorender.com.

\section{Authors' contributions}

EA and $M C$ conceived the study. EA designed, performed and analysed data from all experiments. YZ helped with RNAscope staining and imaging and assisted with microglia isolation from tissue for flow cytometry and bulk RNA sequencing. EA wrote the manuscript. All authors read and approved the final manuscript.

\section{Funding}

This work was supported by NIH grant R01AR072965.

\section{Availability of data and materials}

All datasets used and/or analysed during the current study are available from the corresponding author on reasonable request. Bulk RNA sequencing data may be accessed at the NCBI SRA with accession ID PRJNA658781.

\section{Ethics approval and consent to participate}

All animal experiments were carried out in agreement with the institutional guidelines at Harvard Medical School, following approval of ethical protocols by the local Institutional Animal Care and Use Committee (protocol numbers IS00000748, IS00000111 and IS00002660) and per applicable laws and regulations.

\section{Consent for publication}

Not applicable.

\section{Competing interests}

The authors declare that they have no competing interests.

\section{Author details}

${ }^{1}$ Program in Cellular and Molecular Medicine, Boston Children's Hospital, Boston, MA, USA. Division of Medical Sciences, Harvard Medical School, Boston, MA, USA.

\section{Received: 17 August 2020 Accepted: 19 October 2020} Published online: 12 November 2020

\section{References}

1. Crow MK, Type I. Interferon in the pathogenesis of lupus. J Immunol. 2014; 192:5459-68.

2. Crow YJ, Manel N. Aicardi-Goutières syndrome and the type interferonopathies. Nat Rev Immunol. 2015;15:429-40.

3. Schreiber $\mathrm{G}$, Piehler J. The molecular basis for functional plasticity in type interferon signaling. Trends Immunol. 2015;36:139-49.
4. van Boxel-Dezaire AHH, Rani MRS, Stark GR. Complex modulation of cell typespecific signaling in response to type I interferons. Immunity. 2006;25:361-72.

5. Valentine AD, Meyers CA. Neurobehavioral effects of interferon therapy. Curr Psychiatry Rep. 2005;7:391-5.

6. Schaefer M, Engelbrechta MA, Gut O, Fiebich BL, Bauer J, Schmidt F, et al. Interferon alpha (IFNa) and psychiatric syndromes: a review. Prog NeuroPsychopharmacology Biol Psychiatry. 2002;26:731-46.

7. Scheibel RS, Ph D, Valentine AD, Brien SO, Meyers CA. Cognitive dysfunction and depression during treatment with interferon-alpha and chemotherapy. J Neuropsychiatry Clin Neurosci. 2004;16:185-91.

8. Shiozawa S, Kuroki Y, Kim M, Hirohata S, Ogino T. Interferon alpha in lupus psychosis. Arthritis Rheum. 1992;35:417-22.

9. Jeltsch-David H, Muller S. Neuropsychiatric systemic lupus erythematosus: Pathogenesis and biomarkers. Nat Rev Neurol. 2014;10:579-96.

10. Schafer DP, Lehrman EK, Kautzman AG, Koyama R, Mardinly AR, Yamasaki $R$, et al. Microglia sculpt postnatal neural circuits in an activity and complement-dependent manner. Neuron. 2012;74:691-705.

11. Paolicelli RC, Bolasco G, Pagani F, Maggi L, Scianni M, Panzanelli P, et al. Synaptic pruning by microglia is necessary for normal brain development. Science. 2011;333:1456-8.

12. Nimmerjahn A, Kirchhoff F, Helmchen F. Resting microglial cells are highly dynamic surveillants of brain parenchyma in vivo. Science. 2005;308:1314-9.

13. Wake H, Moorhouse AJ, Jinno S, Kohsaka S, Nabekura J. Resting microglia directly monitor the functional state of synapses in vivo and determine the fate of ischemic terminals. J Neurosci. 2009:13:3974-80.

14. Hong S, Beja-Glasser VF, Nfonoyim BM, Frouin A, Li S, Ramakrishnan S, et al. Complement and microglia mediate early synapse loss in Alzheimer mouse models. Science 2016:352:712-6.

15. Roy ER, Zheng H, Cao W. Type I interferon response drives neuroinflammation and synapse loss in Alzheimer disease. J Clin Invest. 2020;130:1912-30.

16. Sekar A, Bialas AR, de Rivera H, Davis A, Hammond TR, Kamitaki N, et al. Schizophrenia risk from complex variation of complement component 4. Nature. 2016;530:177-83

17. Kim HJ, Cho MH, Shim WH, Kim JK, Jeon EY, Kim DH, et al. Deficient autophagy in microglia impairs synaptic pruning and causes social behavioral defects. Mol Psychiatry. 2016:22:1576-84.

18. Zhan Y, Paolicelli RC, Sforazzini F, Weinhard L, Bolasco G, Pagani F, et al Deficient neuron-microglia signaling results in impaired functional brain connectivity and social behavior. Nat Neurosci. 2014;17:400-6.

19. Zheng L, Kaneko N, Sawamoto K. Minocycline treatment ameliorates interferon-alpha- induced neurogenic defects and depression-like behaviors in mice. Front Cell Neurosci. 2015:9:1-10.

20. Goldmann T, Blank T, Prinz M. Fine-tuning of type I IFN-signaling in microglia - implications for homeostasis, CNS autoimmunity and interferonopathies. Curr Opin Neurobiol. 2016:36:38-42.

21. Deczkowska A, Matcovitch-Natan O, Tsitsou-Kampeli A, Ben-Hamo S, DvirSzternfeld R, Spinrad A, et al. Mef2C restrains microglial inflammatory response and is lost in brain ageing in an IFN-I-dependent manner. Nat Commun. 2017:8:1-13.

22. Hammond TR, Dufort C, Dissing-Olesen L, Giera S, Young A, Wysoker A, et al. Single-cell RNA sequencing of microglia throughout the mouse ifespan and in the injured brain reveals complex cell-state changes. Immunity. 2019:50:253-71 e6.

23. Mathys H, Adaikkan C, Gao F, Young JZ, Manet E, Hemberg M, et al. Temporal tracking of microglia activation in neurodegeneration at singlecell resolution. Cell Rep. 2017;21:366-80.

24. Nomura A, Noto D, Murayama G, Chiba A, Miyake S. Unique primed status of microglia under the systemic autoimmune condition of lupus-prone mice. Arthritis Res Ther. 2019;21:1-17.

25. Vasek MJ, Garber C, Dorsey D, Durrant DM, Bollman B, Soung A, et al. A complement-microglial axis drives synapse loss during virus-induced memory impairment. Nature. 2016:534:538-43.

26. Yona S, Kim KW, Wolf Y, Mildner A, Varol D, Breker M, et al. Fate mapping reveals origins and dynamics of monocytes and tissue macrophages under homeostasis. Immunity. 2013;38:79-91.

27. Butovsky O, Jedrychowski MP, Moore CS, Cialic R, Lanser AJ, Gabriely G, et al. Identification of a unique TGF- $\beta$-dependent molecular and functional signature in microglia. Nat Neurosci. 2014;17:131-43.

28. McQuin C, Goodman A, Chernyshev V, Kamentsky L, Cimini BA, Karhohs KW et al. CellProfiler 3.0: Next-generation image processing for biology. PLoS Biol. 2018;16:e2005970. 
29. Dobin A, Davis CA, Schlesinger F, Drenkow J, Zaleski C, Jha S, et al. STAR: ultrafast universal RNA-seq aligner. Bioinformatics. 2013;29:15-21.

30. Robinson MD, McCarthy DJ, Smyth GK. edgeR: A Bioconductor package for differential expression analysis of digital gene expression data. Bioinformatics. 2009;26:139-40.

31. Raudvere U, Kolberg L, Kuzmin I, Arak T, Adler P, Peterson H, et al. g:Profiler: a web server for functional enrichment analysis and conversions of gene lists (2019 update). Nucleic Acids Res. 2019;47:W191-8.

32. Zheng L, Hitoshi S, Kaneko N, Takao K, Miyakawa T. Mechanisms for interferon-a-induced depression and neural stem cell dysfunction. Stem Cell Rep. 2014;3:73-84.

33. Wang J, Campbell IL, Zhang H. Systemic interferon-a regulates interferonstimulated genes in the central nervous system. Mol Psychiatry. 2008;13: 293-301.

34. Jonasch E. Interferon in oncological practice: review of interferon biology, clinical applications, and toxicities. Oncologist. 2001;6:34-55.

35. Moriyama M, Arakawa Y. Treatment of interferon-a for chronic hepatitis C. Expert Opin Pharmacother. 2006;7:1163-79.

36. Yu M-L, Dai C-Y, Chen S-C, Lee L-P, Hsieh M-Y, Lin Z-Y, et al. High versus standard doses interferon-alpha in the treatment of naïve chronic hepatitis C patients in Taiwan: a 10-year cohort study. BMC Infect Dis. 2005;5:27.

37. Banks WA. From blood-brain barrier to blood-brain interface: new opportunities for CNS drug delivery. Nat Rev Drug Discov. 2016;15:275-92.

38. Raison $\mathrm{CL}$, Demetrashvili M, Capuron L, Miller AH. Neuropsychiatric adverse effects of interferon-a. CNS Drugs. 2005;19:105-23.

39. Mayr N, Zeitlhofer J, Deecke L, Fritz E, Ludwig H, Gisslinger H. Neurological function during long-term therapy with recombinant interferon alpha. J Neuropsychiatry Clin Neurosci. 1999;11:343-8.

40. Gorwood P. Neurobiological mechanisms of anhedonia. Dialogues Clin Neurosci. 2008;10:291-9.

41. Taylor JL, Amann M, Duchateau J, Meeusen R, Rice CL. Neural contributions to muscle fatigue: from the brain to the muscle and back again. Med Sci Sports Exerc. 2016;48:2294-306.

42. Penner I-K, Paul F. Fatigue as a symptom or comorbidity of neurologica diseases. Nat Rev Neurol. 2017:13:662-75.

43. Rusinova I, Forster S, Yu S, Kannan A, Masse M, Cumming H, et al. INTERFER OME v2.0: an updated database of annotated interferon-regulated genes. Nucleic Acids Res. 2013:41:1040-6.

44. Hickman SE, Kingery ND, Ohsumi TK, Borowsky ML, Wang L, Means TK, et al. The microglial sensome revealed by direct RNA sequencing. Nat Neurosci. 2013;16:1896-905.

45. Jimenez JC, Su K, Goldberg AR, Luna VM, Biane JS, Ordek G, et al. Anxiety cells in a hippocampal-hypothalamic circuit. Neuron. 2018;97:670-83 e6.

46. Sigurdsson T, Duvarci S. Hippocampal-prefrontal interactions in cognition, behavior and psychiatric disease. Front Syst Neurosci. 2016;9:1-18.

47. Phillips JR, Hewedi DH, Eissa AM, Moustafa AA. The cerebellum and psychiatric disorders. Front Public Heal. 2015;3:1-8.

48. Moreno-Rius J. The cerebellum in fear and anxiety-related disorders. Prog Neuro-Psychopharmacology Biol Psychiatry. 2018;85:23-32.

49. Hare BD, Duman RS. Prefrontal cortex circuits in depression and anxiety: contribution of discrete neuronal populations and target regions. Mol Psychiatry. 2020;25:2742-58.

50. Korzhevskii DE, Kirik OV. Brain microglia and microglial markers. Neurosci Behav Physiol. 2016:46:284-90.

51. Salemi J, Obregon DF, Cobb A, Reed S, Sadic E, Jin J, et al. Flipping the switches: CD40 and CD45 modulation of microglial activation states in HIV associated dementia (HAD). Mol Neurodegener. 2011;6:1-8.

52. Grabert K, Michoel T, Karavolos MH, Clohisey S, Baillie JK, Stevens MP, et al. Microglial brain region-dependent diversity and selective regional sensitivities to aging. Nat Neurosci. 2016;19:504-16.

53. Blank T, Detje CN, Spieß A, Hagemeyer N, Brendecke SM, Wolfart J, et al. Brain endothelial- and epithelial-specific interferon receptor chain 1 drives virus-induced sickness behavior and cognitive impairment. Immunity. 2016; 44:901-12

54. Orzalli MH, Smith A, Jurado KA, Iwasaki A, Garlick JA, Kagan JC. An antiviral branch of the il-1 signaling pathway restricts immune-evasive virus replication. Mol Cell. 2018;71:825-40 e6.

55. Wang W, Xu L, Brandsma JH, Wang Y, Hakim MS, Zhou X, et al. Convergent transcription of interferon-stimulated genes by tnf- $a$ and ifn- $a$ augments antiviral Activity against HCV and HEV. Sci Rep. 2016;6:1-14
56. Wang W, Xu L, Su J, Peppelenbosch MP, Pan Q. Transcriptional regulation of antiviral interferon-stimulated genes. Trends Microbiol. 2017:25:573-84.

57. Schoggins JW. Interferon-stimulated genes: what do they all do? Annu Rev Virol. 2019:6:567-84

58. Chen Y, Lun ATL, Smyth GK. From reads to genes to pathways: differential expression analysis of RNA-Seq experiments using Rsubread and the edgeR quasi-likelihood pipeline. F1000Research. 2016;5:1438

59. Pan W, Banks WA, Kastin AJ. Permeability of the blood-brain and bloodspinal cord barriers to interferons. J Neuroimmunol. 1997;76:105-11.

60. Smith RA, Norris F, Palmer D, Bernhardt L, Wills RJ. Distribution of alpha interferon in serum and cerebrospinal fluid after systemic administration. Clin Pharmacol Ther. 1985;37:85-8.

61. DePaula-Silva AB, Gorbea C, Doty DJ, Libbey JE, Sanchez JMS, Hanak TJ, et al. Differential transcriptional profiles identify microglial- and macrophage-specific gene markers expressed during virus-induced neuroinflammation. J Neuroinflammation. 2019;16:1-20.

62. Comer AL, Jinadasa T, Sriram B, Phadke RA, Kretsge LN, Nguyen TPH, et al. Increased expression of schizophrenia-associated gene C4 leads to hypoconnectivity of prefrontal cortex and reduced social interaction. PLOS Biol. 2020;18:1-36.

63. Lehrman EK, Wilton DK, Litvina EY, Welsh CA, Chang ST, Frouin A, et al. CD47 protects synapses from excess microglia-mediated pruning during development. Neuron. 2018;100:120-34

64. Jiang C, Song L, Lu C, You Z, Wang Y, Sun L, et al. Analgesic effect of interferonalpha via mu opioid receptor in the rat. Neurochem Int. 2000;36:193-6.

65. Liu C-C, Gao Y-J, Luo H, Berta T, Xu Z-Z, Ji R-R, et al. Interferon alpha inhibits spinal cord synaptic and nociceptive transmission via neuronal-glial interactions. Sci Rep. 2016;6:34356.

66. Schmeisser H, Bekisz J, Zoon KC. New function of type I IFN: induction of autophagy. J Interf Cytokine Res. 2014;34:71-8.

67. Fritsch SD, Weichhart T. Effects of interferons and viruses on metabolism. Front Immunol. 2016;7:1-13.

68. Ahmed D, Jaworski A, Roy D, Willmore W, Golshani A, Cassol E. Transcriptional profiling suggests extensive metabolic rewiring of human and mouse macrophages during early interferon alpha responses. Mediators Inflamm. 2018;2018:1-15.

69. Park A, Iwasaki A. Type I and type III interferons - induction, signaling, evasion, and application to combat COVID-19. Cell Host Microbe. 2020;27:870-8.

70. Sallard E, Lescure F-X, Yazdanpanah Y, Mentre F, Peiffer-Smadja N. Type 1 interferons as a potential treatment against COVID-19. Antiviral Res. 2020; 178:1-4.

71. Zhou Q, Chen V, Shannon CP, Wei X-S, Xiang X, Wang X, et al. Interferona2b treatment for COVID-19. Front Immunol. 2020;11:1-6.

\section{Publisher's Note}

Springer Nature remains neutral with regard to jurisdictional claims in published maps and institutional affiliations.

Ready to submit your research? Choose BMC and benefit from:

- fast, convenient online submission

- thorough peer review by experienced researchers in your field

- rapid publication on acceptance

- support for research data, including large and complex data types

- gold Open Access which fosters wider collaboration and increased citations

- maximum visibility for your research: over $100 \mathrm{M}$ website views per year

At BMC, research is always in progress.

Learn more biomedcentral.com/submissions 